\title{
Informe preliminar sobre el estudio del material cerámico de la factoría fenicia de Essaouira (antigua Mogador)
}

\section{Preliminary Report About the Study of the Ceramic Material of the Phoenician Factory of Essaouira (ancient Mogador)}

\author{
Fernando LóPEz PARDO \\ Publicado por primera vez en Complutum Extra 6/1, 1996, 359-367
}

En estas breves líneas ${ }^{1}$ queremos dar un primer avance del estudio que venimos realizando desde el año 1994 sobre las cerámicas procedentes de las antiguas excavaciones en la factoría fenicia de Essaouira, más conocida en el ámbito arqueológico con el nombre de Mogador. Dicho estudio se inscribe en el marco de la cooperación bilateral hispano-marroquí en temas de arqueología y patrimonio, de cuyo impulso tanto debemos a Manuel Fernández-Miranda.

Hasta hace poco tiempo, la documentación marroquí sobre el periodo fenicio que había visto la luz era francamente escasa y de carácter muy desigual, por ello había contribuido poco al debate sobre la expansión fenicio-púnica en Occidente. Era una imagen fiel de lo que había ocurrido con España hasta hace dos décadas y con Portugal hasta hace muy pocos años. Si repasamos los trabajos de síntesis más actuales podemos darnos cuenta del carácter totalmente obsoleto de las poquísimas noticias recogidas sobre el país norteafricano y sus escasas repercusiones en el análisis general.

Uno de los objetivos básicos de este estudio es, pues, alcanzar un mayor conocimiento de un período histórico aún por descubrir en la fachada atlántica africana y cuyo marco cronológico comprende los siglos VIII al VI a.C. De esa época tenemos sólo unas difusas nociones de carácter histórico que proceden en su mayoría de una limitada documentación arqueológica escasamente procesada y que se refiere casi en exclusiva a dos yacimientos, Lixus y Essaouira, separados entre sí por cientos de kilómetros.

Profundizar en el conocimiento de la cultura material fenicia es a su vez paso necesario para el estudio de la interacción y posterior asimilación fenicios-población autóctona en el proceso de evolución histórica de las poblaciones de los valles costeros marroquíes en el periodo orientalizante.

En este contexto el reestudio de los materiales cerámicos de Essaouira y su publicación continúa el camino iniciado con tanta fortuna por el congreso sobre Lixus en

\footnotetext{
1 El Institut National des Sciences de l'Archéologie el du Patrimoine de Marruecos (INSAP) ha autorizado la publicación de este trabajo, $\mathrm{N}^{\circ} 210 / 070$. El proyecto en el cual se inserta ha sido posible gracias a la ayuda inestimable de la Direction Générale d'Archeólogie et du Patrimoine de Marruecos y al patrocinio del Ministerio de Cultura español.
} 
1989, poniendo a disposición de los investigadores que se dedican a estudiar este y otros ámbitos regionales una documentación de la cual se conocía menos de un $10 \%$.

Por otra parte, al igual que el coloquio sobre la ciudad norteafricana fue un foro de reflexión y estudio previo al inicio de los trabajos arqueológicos en el importante yacimiento de Lixus, el estudio de las cerámicas de la factoría fenicia de Essaouira está sirviendo y servirá modestamente para desarrollar el proyecto lixita en la medida en que provee elementos de comparación y análisis para los restos exhumados y por sacar del otro gran yacimiento fenicio localizado en tierras atlánticas africanas.

\section{Los trabajos anteriores sobre la factoría fenicia de Essaouira}

La isla donde se encuentra la factoría está situada a casi $800 \mathrm{~km}$ del Cabo Espartel, y aunque en la actualidad se halla en medio de la ensenada del uadi Ksob, en un lejano pasado, difícil de medir, formaba un archipiélago con el solar de la localidad actual. A lo largo de la uniforme costa atlántica africana, el islote o los islotes de Essaouira eran en la antigüedad, junto con el de Mohamedia, los únicos de esta amplia línea costera. ${ }^{2}$

El islote, de pequeñas dimensiones y con escasos recursos para la subsistencia si exceptuamos la pesca, tenía a pesar de ello algunos de los rasgos más apreciados por los fenicios para instalar una factoría: aislamiento y seguridad. Rasgos que se repiten en otro enclave fenicio de peores condiciones de subsistencia, la isla del faro de Rachgoun (Argelia) que albergó un asentamiento permanente.

Sobre la isla de Essauira, la única en la que por ahora se han descubierto vestigios antiguos, se han hecho converger dos tradiciones literarias antiguas. La primera se refiere a las "Islas Purpurarias" del rey mauritano Iuba II, cuya tintura era especialmente apreciada en época romana. En 1950 dos profesores del Liceo de la localidad, J. Desjacques y P. Koerbelé, intentaron descubrir las pruebas de la obtención de la famosa tintura en el lugar. Pero a pesar de sus esfuerzos ${ }^{3}$ y los que le siguieron de A. Jodin, ${ }^{4}$ nunca dieron ni con los amontonamientos de malacofauna relacionados con la tintura, ni con las estructuras artesanales propias de esa actividad.

Sin embargo, tan intensa búsqueda dio otros frutos, los vestigios de una factoría fenicia, identificada desde el primer instante como tal a través de sus numerosas inscripciones sobre cerámica. A partir de ese momento se hace converger también sobre Essaouira una segunda tradición literaria igual de problemática: la que se refiere a la isla de Cerne, considerada la más alejada localidad semita de la costa atlántica africana, reiteradamente citada en las fuentes greco-latinas.

Con tales premisas se iniciaron las excavaciones en el yacimiento, primero bajo la dirección de P. Cintas ${ }^{5}$ y después con A. Jodin ${ }^{6}$ como autor, que nos presentaron, sobre todo este último, excelentes memorias de sus trabajos arqueológicos. Si bien no

\footnotetext{
2 JoDIN 1966, 5.

3 Desjacques - Koeberlé 1955.

4 JODIN 1967.

5 CinTas 1954.

6 JoDIN 1957; ID. 1966.
} 
fue posible descubrir el rastro de la regia industria de la púrpura ni saber si los restos exhumados pertenecían a los más lejanos colonos semitas, se puede afirmar que los hallazgos sacados a la luz han tenido similar importancia. Por ejemplo podemos citar el más importante conjunto epigráfico fenicio del Extremo Occidente ${ }^{7}$ con más de un centenar de graffiti sobre cerámica que nos ilustran sobre la antroponimia y los usos socio-culturales de los comerciantes fenicios. Por otro lado, se destacaron aspectos sorprendentes para la época de los descubrimientos, como el notable parecido de las cerámicas de Essaouira con las de las factorías del sur de la Península Ibérica y de la costa argelina. Además la inexistencia de construcciones fijas en la isla hacía inevitable recordar el texto de Pseudo Escílace ${ }^{8}$ que señala que los fenicios al llegar a la isla de Cerne se albergaban en tiendas, y por lo tanto cabía sospechar que se trataba de una factoría estacional.

La frecuentación del enclave debió durar más de cien años, desde mediados del s. VII a.C. hasta la mitad del s. VI a.C. según nos sugiere A. Jodin. ${ }^{9}$ La permanencia durante ese tiempo de un hábitat sin construcciones fijas así como las peculiaridades de sus hallazgos nos hicieron reconocer a Essaouira como una factoría en el sentido más riguroso del término. ${ }^{10} \mathrm{Como}$ un establecimiento comercial con lugares de almacenaje, en el que residen temporal o permanentemente agentes de comercio. Lo cual confería al yacimiento un valor paradigmático para los comienzos de la colonización fenicia en Occidente, en la medida en que sería posible a través de sus hallazgos extraer informaciones valiosas extrapolables a la fase inicial de otros asentamientos, que por su perduración con construcciones sólidas habrían borrado en gran medida la fase inicial de su instalación, la cual por lo general habría durado muy poco tiempo.

Con esta perspectiva el estudio ceramológico que hemos emprendido tenía unos alicientes añadidos a los propios de un reexamen de materiales procedentes de excavaciones antiguas. Al encontrarnos ante un tipo de hábitat diferente y un contexto socio-económico también distinto al de las factorías consolidadas, esta diferencia se tuvo que plasmar en la cultura material de diferentes maneras. Una de ellas ya la pusimos de manifiesto al destacar la sorprendente cantidad de graffiti sobre cerámicas fenicias halladas en el lugar, en proporciones muy superiores a cualquier yacimiento fenicio excavado en el Extremo Occidente. El reexamen de los materiales de Essaouira nos ha permitido de momento descubrir dieciocho nuevos graffiti. ${ }^{11} \mathrm{Se}$ trata de inscripciones de carácter muy modesto, casi siempre un signo o letra, pero que nos ha permitido confirmar mediante el estudio de los soportes la idea de que se trata de recipientes marcados para un uso particularizado de los mismos, debido a la composición no familiar del grupo humano que año tras año se desplazaba a la isla.

Otra línea de trabajo que nos proponemos seguir, y de la que aquí queremos hacer una primera presentación, es el análisis cuantitativo de tipos cerámicos. No se trata

7 Février, 1966, $n^{\circ}$ 22-122; Amadasi Guzzo 1992; Ruiz Cabrero - López Pardo 1996.

8 Ps. Scyl. 112, G.G.IVL, 94.

9 Jodin 1960, 48-9.

10 López Pardo 1992.

11 Ruiz Cabrero - López Pardo 1996. 
todavía de un estudio comparativo con otros yacimientos, sino de una primera aproximación circunscrita al yacimiento.

\section{Cerámicas de Essaouira: avance cuantitativo}

Antes de comenzar el trabajo y sin conocer los fondos del Museo de Rabat, creíamos que nuestra labor iba a consistir en una simple repetición actualizada de los dibujos y un análisis más detallado de los materiales ya publicados por P. Cintas y A. Jodin, pero en realidad nos encontramos con una gran cantidad de material inédito, incluso una parte de él estaba sin clasificar almacenado en cajas. La primera fase del trabajo se desarrolló pues en el Musée Archéologique de Rabat entre los días 1 y 15 de Octubre de 1994 con los materiales que se encontraban guardados en las vitrinas y en los depósitos del museo, llegando a examinar más de cinco mil piezas. Separamos los fragmentos atípicos de aquellos otros de los que era posible reconocer su forma y establecimos las cantidades por tipos. Se hicieron fichas y se dibujaron los fragmentos que nos parecieron más significativos, un total de 495 , llegando a fotografiar unos 150. ${ }^{12}$

Para el presente trabajo sin embargo se ha seguido un criterio diferente. Las piezas contabilizadas debían tener obligatoriamente el borde, descartándose para la encuesta otros tipos de fragmentos, con el fin de no alterar el valor estadístico del muestreo, ya que como es sabido algunas formas son fácilmente reconocibles por otros criterios como la decoración, la pasta o la simple curvatura de la base, mientras que para otras es casi imprescindible que se haya conservado el borde para poder identificarlas. De tal manera que un criterio múltiple de identificación nos hubiera permitido reconocer más piezas de un tipo que de otro sin ser reflejo fiel de su proporcionalidad en el yacimiento, sino de nuestra capacidad para distinguirlas.

Para valorar en su justa medida el muestreo hay que tener en cuenta algunas limitaciones. En cualquier excavación es habitual desembarazarse de una parte de la ingente cantidad de tiestos que aparecen, por ello los materiales depositados en el Museo no tienen porqué ser reflejo exacto de lo que fue apareciendo en Essaouira. El problema en nuestro caso es saber cuáles fueron los criterios seguidos a la hora de desechar unos fragmentos y no otros. Esta cuestión creemos que afecta especialmente a las cerámicas llamadas comunes y las realizadas a mano, que suelen ser las que se desechan con más facilidad a pie de corte, y que como comentaremos más adelante debió ser la práctica habitual en el yacimiento. También tiene relación con el hecho de que se trata de una colección de museo el que no hayamos podido documentar la cerámica griega procedente del yacimiento, sencillamente porque no la hemos encontrado. No sé si porque nos ha pasado desapercibida la caja o cajas en los depósitos del museo o bien porque no se encuentra en él. También se echarán de menos las ánforas,

12 Quiero mostrar mi más vivo agradecimiento a Teresa Monsoriú Sanz, Isabel Toro Rueda y Noé Villaverde Vega por su colaboración entusiasta y de enorme calidad técnica en el trabajo de laboratorio llevado a cabo en el Museo de Rabat. 


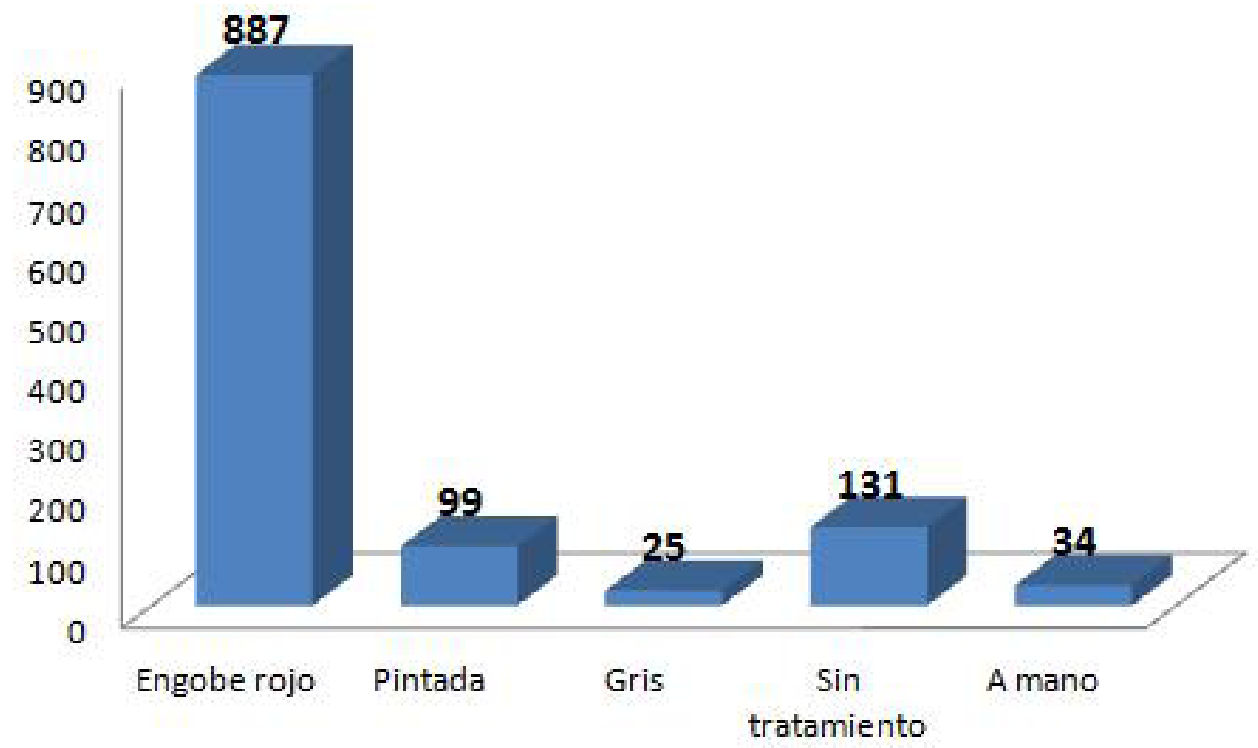

Fig. 1. Clasificación según la fabricación y el tratamiento superficial.

y la razón es que están siendo estudiadas por otro investigador y no queremos interferir en sus resultados.

La cuantificación de la cerámica según criterios técnicos de fabricación y decoración es muy reveladora como se puede apreciar en la figura 1 (Fig. 1).

Cerámica de engobe rojo. Ésta es la más abundante en los depósitos, llegando a superar al resto en su conjunto. El engobe rojo no es sin embargo un tratamiento superficial usado aleatoriamente, a pesar del gusto de los fenicios occidentales por el mismo, sino que éste parece aplicarse a formas cerámicas muy determinadas, siendo muy infrecuente que se aplique este tratamiento a formas que tradicionalmente no se decoran o se decoran de otra manera, por ejemplo las ánforas, las jarras, los pithoi y los morteros. El engobe rojo parece ser característico de la mayor parte de la vajilla de mesa y de las lucernas.

En las cerámicas de Essaouira este engobe férrico mezclado con arcilla muy fina está siempre bruñido, realizado siguiendo el movimiento del torno, excepto en las lucernas y en las formas demasiado delgadas como los jarros de boca de seta y los trilobulados, en cuyo caso el pulido se hace con movimiento manual. En alguna ocasión bajo el engobe rojo se detecta otro engobe de aspecto lechoso, con un considerable componente caolínico, que hemos podido documentar en platos, cuencos de borde en disminución, en un cuenco carenado de borde recto vuelto hacia afuera y en algunas lucernas de pico.

Cerámica pintada. Tampoco es arbitraria la adecuación de formas con la decoración pintada. En Essaouira la pintura se reserva casi exclusivamente a tres formas muy características: las jarras de cuello recto estrecho, los pithoi, no excesivamente 


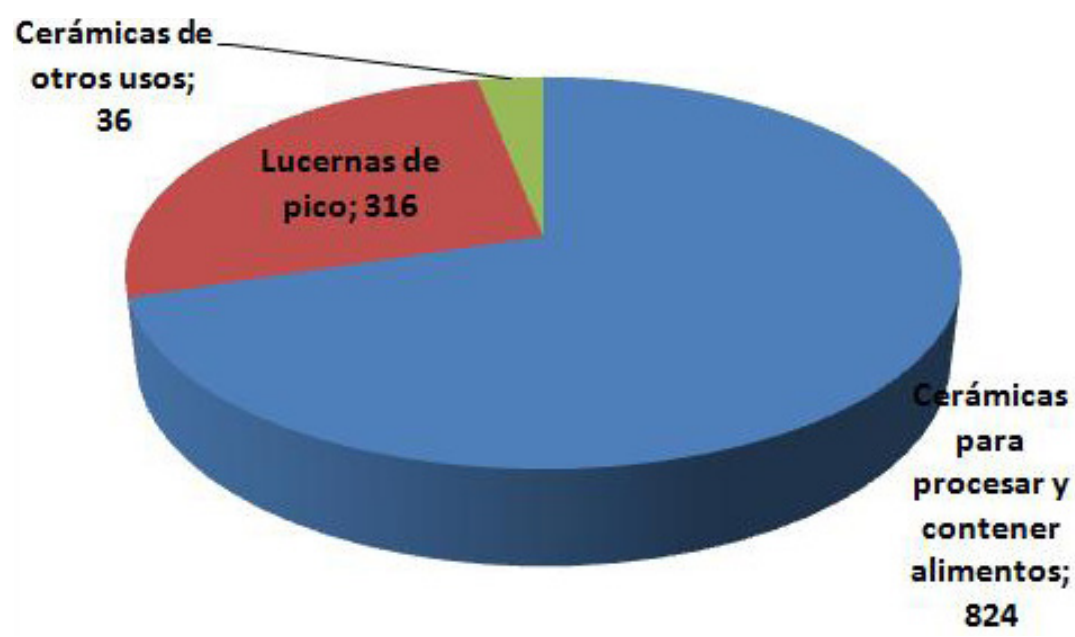

Fig. 2. Distribución por usos.

grandes, ambos dedicados a contener líquidos y por último los cuencos hemiesféricos, casi siempre decorados con líneas concéntricas en su interior. La decoración pintada, que siempre consiste en líneas y bandas suele ser muy repetitiva, líneas de color rojo o castaño, y bandas del mismo color a veces delimitadas por finas líneas negras. Es frecuente en las jarras y pithoi que la decoración se trace sobre la superficie engobada en color lechoso que puede abarcar todo o parte del vaso.

Cerámica gris. La cerámica gris es muy escasa, la menos representada en Essaouira, a pesar de nuestro empeño por recoger todos los fragmentos posibles. Parece haber una especial predilección por los cuencos hemiesféricos de gran tamaño (15), siendo enormemente raras otras formas.

Cerámica sin tratamiento. No puede ser considerada aquí como cerámica común, o con un uso específico, ya que el simple alisado o el engobe se aplican a formas muy distintas que vemos otras veces con diferentes tratamientos, lucernas y cuencos de engobe rojo y cuencos hemiesféricos pintados, etc.

Ello nos induce a pensar que una parte muy considerable de la cerámica hecha a torno parece provenir de un mismo sitio, según nos sugieren además otros indicios, como la similitud de las pastas en cuanto a textura, colorido, etc., la uniformidad del engobe rojo y la existencia del mismo tipo de engobe de base tanto en las cerámicas pintadas, en las que no tienen tratamiento y en los platos y cuencos de engobe rojo. Cuestión que solamente queremos sugerir por ahora.

Cerámica hecha a mano. Sólo en apariencia es normal tan escaso número en esta factoría fenicia, pero en realidad no lo es tanto puesto que no se ha encontrado 


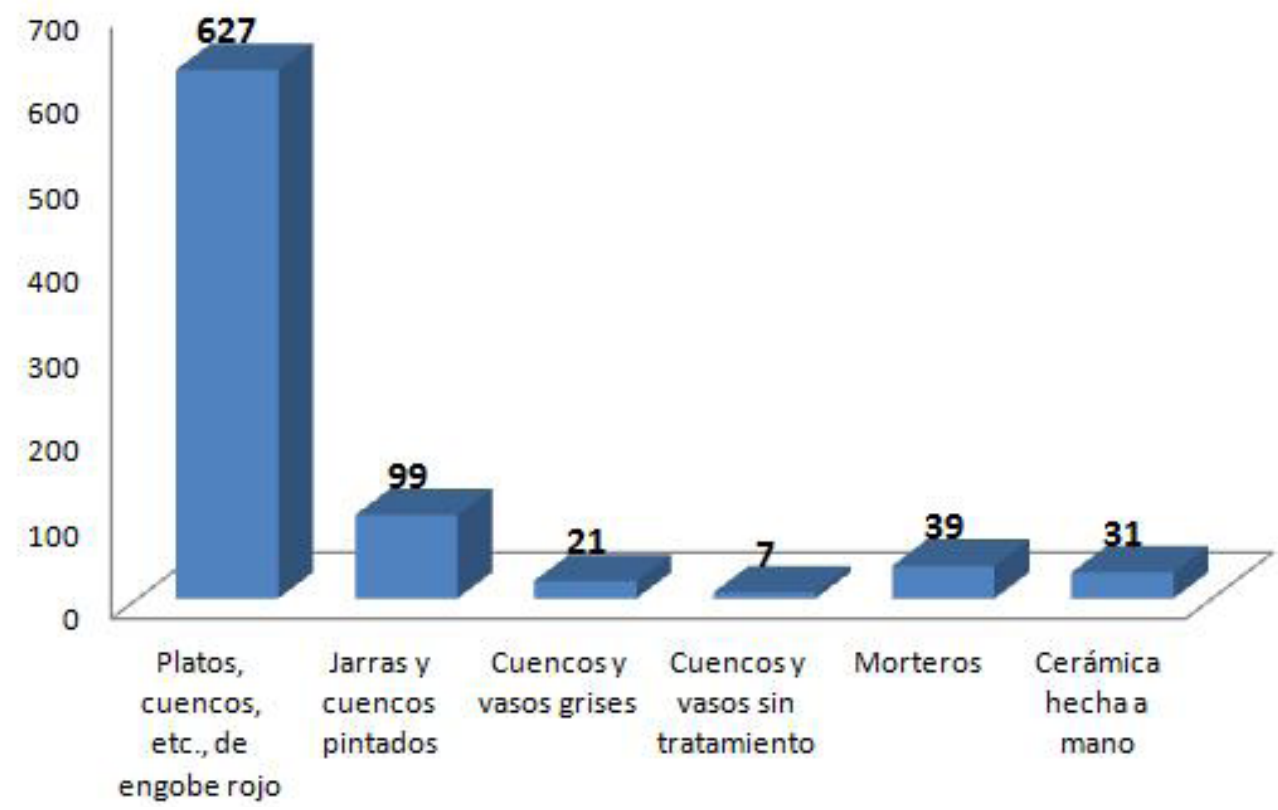

Fig. 3. Cerámica para procesar y contener alimentos, clasificada por técnicas de fabricación.

cerámica a torno que se pusiera al fuego, cuestión que analizamos unas líneas más adelante.

También es eficaz plantearse otros criterios de clasificación, como el relativo a los usos (Fig. 2), de tanto interés para conocer la vida cotidiana en la factoría. Todavía es prematuro pronunciarse sobre la relación proporcional entre cerámicas de unos y otros usos hasta que no se establezca una comparación con otros yacimientos, aunque no deja de sorprender la gran cantidad de lucernas de dos picos. A continuación presentamos desglosados cada uno de estos tres tipos.

De la cerámica que tiene que ver con la alimentación presentamos dos diagramas de barras que son muy expresivos (figs. 3 y 4). El primero tiene que ver con la evidente relación que suele existir entre el tipo de tratamiento que se aplica sobre la superficie del vaso y el destino que se pretende darle. Desde los tratamientos meramente funcionales, como la superficie rugosa de un mortero, o la pulida de un plato, hasta aquellos otros tratamientos más ornamentales, como la decoración pintada de las jarras o incluso el color gris de algunos cuencos con el fin de ser diferenciados por su color, todos ellos nos sugieren, en función de sus cantidades, unos hábitos alimenticios propios de zonas y épocas cálidas, con la característica escasa elaboración de los alimentos. Existe un claro predominio de la vajilla de mesa, la mayoría de ella terminada con engobe rojo, sobre el resto de las cerámicas para tratar o contener alimentos. Aunque la diferencia parece abrumadora respecto a las demás cabe la sospecha de 


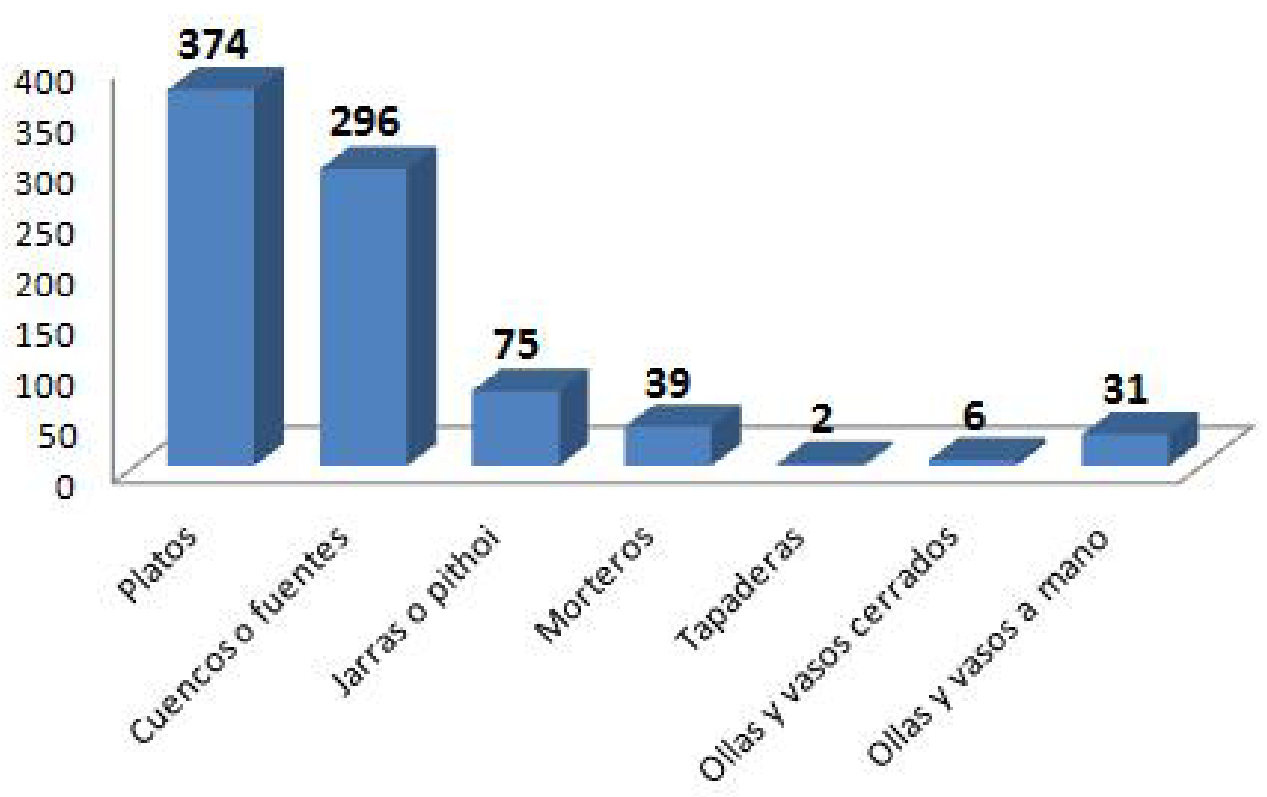

Fig. 4. Cerámica para procesar y contener alimentos, clasificada por formas.

que la cerámica de aspecto más vulgar, sin apenas tratamiento, pudo ser desechada en parte durante el proceso de excavación.

El segundo diagrama de cerámica relacionada con los alimentos, donde se cuantifica ésta según las formas, nos da una visión más acentuada, si cabe, del predominio de vasos para comer y beber sobre aquéllos que se necesitan para elaborar los alimentos.

Platos, siempre en engobe rojo, no aparecen jamás con otro tratamiento en esta factoría. Los de borde redondeado reseñados suman 144. Doce de las piezas dibujadas tienen $26 \mathrm{~cm}$ de diámetro, cuyo borde oscila entre 6 y $7 \mathrm{~cm}$ de anchura. El resto de las piezas oscila entre 29 y $23 \mathrm{~cm}$ de diámetro, sin detectarse una relación clara entre el diámetro y el ancho del borde. Hay, por ejemplo, una pieza de $28 \mathrm{~cm}$ de diámetro con $5,5 \mathrm{~cm}$ de borde y otra de $24 \mathrm{~cm}$ de diámetro y $7 \mathrm{~cm}$ de borde. Los pocos recipientes de menor diámetro, entre 13,5 y $23 \mathrm{~cm}$, tienden a tener un borde algo más estrecho, entre 4 y $5 \mathrm{~cm}$. Los platos de borde acanalado o moldurado son en total 230 . Entre los bordes dibujados encontramos una concentración uniforme entre los $24 \mathrm{y}$ $30 \mathrm{~cm}$ de diámetro con un labio que oscila entre los 6 y $8 \mathrm{~cm}$ de ancho. Muy pocas son las piezas pequeñas, con labio ligeramente más estrecho, una de 16 de diámetro con $3,5 \mathrm{~cm}$ de borde y otra de $20 \mathrm{~cm}$ de diámetro con $5,5 \mathrm{~cm}$.

Por el momento no se puede hablar de una relación estrecha y mecánica entre el diámetro de las piezas y el ancho del borde, a pesar de lo que se venía diciendo hasta ahora para este sitio. Por otro lado, a pesar de que se documenta una mayor proporción de platos de borde acanalado o moldurado que de platos de borde redondeado, la 
diferencia no es tan grande como se había señalado. En nuestros cálculos la proporción parece ser de 1 a 1,66.

Cuencos hemiesféricos: de engobe rojo, 17; pintados, 18; sin tratamiento, 3; grises, 15. Parece existir un equilibrio en cuanto a los tratamientos en esta forma, que es claramente minoritaria en engobe rojo, pero la más común en cerámica gris.

Cuencos con acanaladuras sólo hemos encontrado dos, tienen un diámetro de 29 $\mathrm{cm}$ y son de engobe rojo, también son muy infrecuentes en otros yacimientos.

Cuencos carenados con borde en disminución se cuentan 45, y al igual que ocurre con los platos, esta forma aparece exclusivamente acabada en engobe rojo.

Cuencos o fuentes carenados de borde vuelto hacia afuera: de borde recto se dibujaron 58 y de borde curvo 23. Sin dibujar se contaron en total 103. La abrumadora mayoría son de engobe rojo, pero dos no tienen engobe aunque fueron bruñidos, otros tres fueron pintados y otros dos no recibieron ningún tratamiento, además de haberse encontrado otros cuatro en cerámica gris.

Cuencos de formas raras, 3 .

Morteros trípodes (39). A pesar de contar con una gran variedad de formas (en este sentido no se parece en nada al resto de las cerámicas de Essaouira), en cuanto a tamaño parece haber una gran uniformidad. 25 de los morteros tienen un diámetro que oscila entre los 18 y $22 \mathrm{~cm}$. Ninguno es menor a $18 \mathrm{~cm}$. De los nueve restantes 7 miden entre 23 y $28 \mathrm{~cm}$ y sólo dos 32 y $33 \mathrm{~cm}$.

Jarras pintadas de cuello recto estrecho, dibujadas 22. Pithoi de cuello ancho con asas adosadas al borde, dibujados 18, De los dos grupos, sin dibujar hay 35 .

Una tapadera pintada y otra gris.

Aunque las ollas y vasos de perfil en $\mathbf{S}$ los encontramos con todo tipo de tratamiento superficial, su número es muy escaso. En engobe rojo, dos fragmentos, igual que en cerámica pintada y dos ollas comunes simplemente alisadas y por último una gris.

Cerámica hecha a mano (31). En cuanto a las formas, destacan por su abundancia las ollas (16), contamos con un pithos, algunas escasas formas abiertas y muy raros bordes salientes.

Llegados a este punto queremos plantear la cuestión de cuál de los tipos de cerámica descritos hasta ahora se ponía al fuego, se utilizaba para cocinar. Claramente hemos de descartar la cerámica de engobe rojo, que por tratamiento y por la falta de huellas se aprecia que jamás estuvo sobre el fuego. Con las cerámicas pintadas y las grises ocurre otro tanto de lo mismo. Sólo nos queda la cerámica sin tratamiento como la única posible destinada a esta tarea. De entre ellas hay que descartar por su uso las botellas, las jarritas, los trípodes y naturalmente los cuencos, demasiado abiertos, frecuentemente engobados y sin manchas de cocción. Por otro lado no hemos encontrado entre la cerámica a torno los rasgos que caracterizan este tipo de cerámica destinada al hogar: desgrasantes gruesos, especialmente cuarzo, falta de cohesión de la pasta, formas groseras, etc. Lo cual evidentemente nos obliga a derivar la pesquisa por otros derroteros.

El problema de reconocer la cerámica de cocina, muy evidente en Essaouira, parece repetirse en otros yacimientos fenicios en general, pues no es fácil encontrar 
entre la cerámica fenicia a torno, las cerámicas de formas cerradas y superficie rugosa propias de este uso. Ello nos obliga en este caso a volver la vista sobre las cerámicas hechas a mano. En los depósitos del museo hemos podido contabilizar 52 fragmentos de cerámica a mano, de los cuales 31 son bordes. Cantidad sorprendentemente baja que seguramente no refleja para nada la proporción real respecto a las hechas a torno. Se trata de cerámica de pasta con partículas grandes de desgrasante, la mayoría de superficie rugosa, aunque algunas fueron someramente bruñidas y con cocción defectuosa con manchas negras en muchos casos. Las decoraciones más habituales son las digitaciones, el escobillado o las acanaladuras. En cuanto a las formas, como ya hemos señalado destacan por su abundancia las ollas (16), y en menor medida las formas abiertas. Aunque algunas de ellas no se utilizaban para el fuego, pues conservan un engobe marrón uniforme, otras, la mayoría, tienen la superficie rugosa con huellas de quemado en el exterior. Parece pues muy probable que este tipo de cerámica era el que en ausencia de otra hecha a torno cumpliese la misma función en la cocina.

Cabe también preguntamos a quién atribuir su fabricación. El hallazgo de tres bordes de lucernas de pico hechas a mano abogaría por una fabricación in situ, de aquello que les faltaba momentáneamente a los fenicios. Por otra parte, recuerdan las cerámicas a mano de Essaouira a las de Huelva, con sus cordones digitados, mamelones, decoraciones incisas, etc. Pero también, como ya señaló A. Jodin ${ }^{13}$, se parecen mucho a las cerámicas de la Edad del Bronce de la región, de la cueva de El Khril en el Ras Achakar y en Dar-es-Soltan y en Temara, y a las recogidas por M. Tarradell en Lixus. Lo cual permite sugerir o bien que fueron adquiridas en los poblados próximos o bien que fueron fabricadas en el asentamiento fenicio por mujeres del país.

Curiosamente en Essaouira sólo hemos localizado lámparas con dos picos a pesar del considerable número de fragmentos recogidos, 311 (fig. 5), cuando en muchos yacimientos occidentales no es extraño encontrar lucernas de un solo pico entre las otras aún en los siglos VII y VI a.C. También es de destacar la variedad de tratamientos aplicados a este tipo de objeto. Si bien es mayoritaria la lámpara con un engobe rojo lustrado a mano con el recipiente parado, no es infrecuente encontrar lucernas que antes de este tratamiento recibieron un engobe claro. Otras no contaron con el clásico engobe rojo, simplemente fueron alisadas, y en algunos casos fueron tratadas sin más con ese engobe claro del que venimos hablando. Da la impresión de que contáramos con lucernas en todos los estadios posibles de su proceso de acabado: alisadas, alisadas y con engobe claro, alisadas, con engobe claro y con engobe rojo, alisadas más engobe rojo. Se han identificado además cuatro lucernas grises, cuya coloración ha sido obtenida mediante una cocción claramente reductora. Esta combinación de tratamientos está indicando sin duda una gran uniformidad en la producción que parece ser extrapolable a otras formas cerámicas como los platos o los cuencos, que habrá que analizar detenidamente. Los tres fragmentos de lucernas hechas a mano, nos recuerdan que Essaouira es una factoría estacional donde no se fabrica la cerámica a torno, se trata pues de una fabricación de emergencia, fenómeno al que se asocia

13 Jodin 1966, 166-169. 


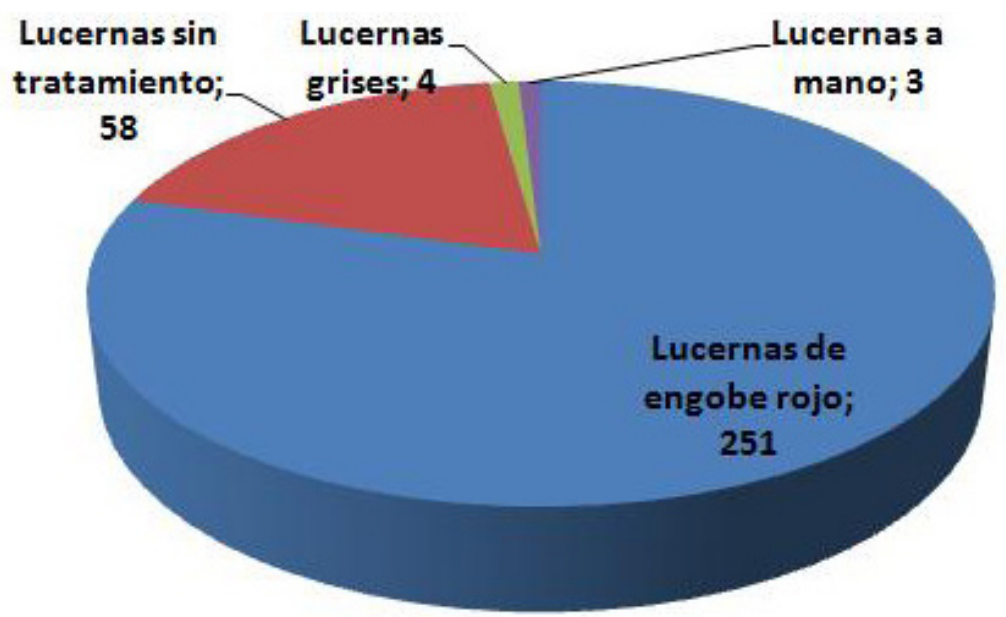

Fig. 5. Lucernas de dos picos.

la frecuentísima reparación de las cerámicas rotas, que en Essaouira alcanza cotas insospechadas.

La mayoría de los recipientes considerados de otros usos tienen que ver con el cuidado personal (fig. 6).

Jarros de boca de seta (4). Es un objeto que suele ser frecuente en los yacimientos occidentales en el siglo VIII a.C. pero en los siglos VII y VI a.C. su utilización es muy limitada, como parece desprenderse también de Essaouira. Los cuatro bordes hallados tienen un labio que oscila entre los 8 y $9 \mathrm{~cm}$. Jarros de boca trilobulada, (4). Quemaperfumes, (1). Este raro recipiente tiene la misma forma que los cuencos carenados de borde recto vuelto hacia afuera. En este caso se pudo identificar por la rotura de la parte central de la pieza inferior. Jarritas, (15). Todas con engobe de color rosado. Botellas de aceite perfumado, (12). Casi siempre tratadas con un engobe que a veces es del mismo color que la pasta. Todas ellas menos una tienen el borde engrosado y hacia adentro formando una concavidad interior junto a la boca.

En suma hemos tratado aquí de presentar una información global acerca del conjunto cerámico de la factoría fenicia de Essaouira. Contábamos con algunas limitaciones de partida que han reducido la fiabilidad de la cuantificación, en tanto en cuanto desconocemos los tipos cerámicos que fueron desechados y en qué medida en el proceso de excavación. Así como tampoco estamos seguros de que el material hallado en los depósitos del musco de Rabat sea el total de lo recuperado en el yacimiento. Por ejemplo es muy probable que una parte de los graffiti descubiertos en la primera época de excavaciones no se conserve en esa institución. A pesar de todo ello es innegable el interés que tiene clasificar todo el conjunto cerámico pues se trata de 


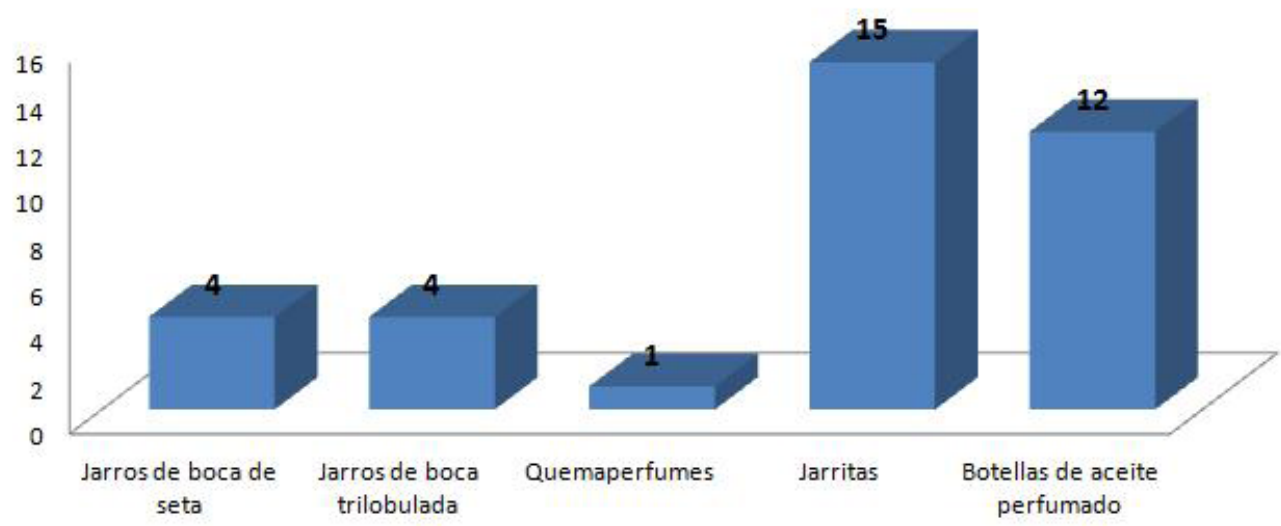

Fig. 6. Cerámica de otros usos.

una muestra muy amplia de las cerámicas de la factoría ya que provienen de varias campañas de excavación.

La documentación arqueológica de Essaouira era ya conocida aunque sólo en una pequeña parte, mientras el resto permanecía inédito, por ello ha sido posible realizar el estudio sobre un mayor número de especímenes, con todo lo que conlleva de mayor precisión en los resultados y de corrección o matización de conclusiones anteriores.

Nuestras conclusiones no dejan de ser menos provisionales dado que lo realizado hasta ahora es la primera fase del proyecto y no se han establecido aún comparaciones con otros yacimientos. A pesar de ello ya podemos detectar similitudes con otras factorías y colonias fenicias como es el gran parecido de los tipos cerámicos, pero también vemos en Essaouira ciertos rasgos propios como la mayor o menor presencia de algunos tipos cerámicos, así sucede con las lucernas, tan abundantes aquí, o la existencia de producciones de emergencia hechas a mano y las numerosísimas reparaciones de todo tipo de cerámica.

También se puede destacar la problemática de la cerámica para el fuego y las cuestiones relacionadas con la cerámica hecha a mano. Así como el abultado número de platos y cuencos realizados en engobe rojo que señalan la primacía de la cerámica para la mesa respecto de la que se utiliza en la cocina y sus implicaciones sobre las costumbres alimenticias de estos fenicios desplazados a la isla de Essaouira.

\section{Bibliografía}

Amadasi Guzzo, M. G. (1992): "Notes sur les graffitis phéniciens de Mogador”, [en] Lixus. Actes du Colloque de Larache (8-11 novembre 1989), (=Collection de l'École française de Rome 166), Roma, 155-157.

Cintas, P. (1954): Contribution à l'étude de l'expansion carthaginoise au Maroc (=Publications de l'Institut des Hautes Études Marocaines 56), Paris. 
Desjacques, J. - Koeberlé, P. (1955): "Mogador et les Îles Purpuraires", Hesperis 42, 199-203.

FÉVRIER. J. (1966): "Inscriptions puniques et neopuniques", [en] Inscriptions antiques du Maroc I, Paris, 81-132.

JoDIN, A.

(1957): "Note préliminaire sur l'établissement pre-Romain de Mogador (campagnes 1956-1957)", BAM 2, 9-40.

(1966): Mogador. Comptoir phénicien du Maroc atlantique (=Études et travaux d'archéologie marocaine 2), Rabat.

(1967): Les établissements du roi Juba II aux îles purpuraires (Mogador), (=Études et travaux d'archéologie marocaine 3), Tanger.

LóPEZ PARDO, F. (1992): "Mogador "factoría extrema" y la cuestión del comercio fenicio en la costa atlántica africana", [en] Actes du ve Colloque International d'Histoire et Archéologie de l'Afrique du Nord (Avignon, 1990), Paris, 277-296.

Ruiz Cabrero, L. A. - López Pardo, F. (1996): "Cerámicas fenicias con graffitti de la isla de Essaouira (antigua Mogador. Marruecos)", Rivista di Studi Fenici 24/2, 153-179. 